\title{
Diversity, Emergence, Resilience: Guides for A New Generation of Ecohealth Research and Practice
}

Ecohealth has emerged as a nexus of scholarly and practical effort at a time of considerable transition in research, policy, practice, and education. Amidst this flux, critical reflection is important, especially regarding where ecohealth is headed as a transdisciplinary field and how ecohealth positions itself among a series of iterative and converging efforts. Ten years after founding discussions led to the establishment of the journal EcoHealth, and 5 years from the establishment of the International Association for Ecology \& Health, is a timely opportunity to reflect on the past, present, and future of the field and the spaces that ecohealth is growing into.

Impetus for the field of ecohealth emerged along with other 'turn of 21st century' efforts. When launched in 2004, the journal EcoHealth was noted to draw on the momentum of past work, including the journals 'Ecosystem Health' and 'Global Change and Human Health', plus growing interest in a journal to represent Conservation Medicine and related fields. By acknowledging these precedents, the founding Editorial of EcoHealth encouraged the emerging field to be seen in the context of parallel and complementary efforts, and described the collective endeavour as a "transdisciplinary imperative for a sustainable future" (Wilcox et al. 2004). The development of ecohealth in research, policy, practice, and education has been heavily informed by scholarly lineages that include the development of ecosystem approaches to health; rapid expansion of the field of disease ecology; richer understanding of complex ecosystem dynamics and their relationships with human well-being across cultures and societies; and the associated recognition of the social-ecological context for animal and human health. Recent efforts to reflect on and consolidate the influence of these precedents provide an overview of some of the foundational lineages of ecohealth (Webb et al. 2010; Parkes 2011; Waltner-Toews 2011; Zinsstag et al. 2011; Charron 2012). Interweaving and building on diverse lines of inquiry and scholarship over the last decade has led to ecohealth being described as a rich 'tapestry' of approaches. Among these converging lineages, the influence of international conventions, declarations and assessments should not be overlooked.

Ecohealth is emerging as a 'teenager' at the same time as other celebrations of international efforts. The Ottawa Charter, providing the foundation for a socio-ecological basis for promotion of health and well-being, has just celebrated its 25 th anniversary, and the Rio +20 celebrations provide a potent reminder of the need for practical, integrated, intersectoral actions that recognize the influence of ecosystem sustainability on both social and environmental determinants of health. The interconnections among the Ottawa Charter, the Rio Declaration and other international conventions are highlighted by recent efforts such as the 'Healthy People Healthy Wetlands' efforts of the Ramsar Convention on Wetlands, and the 'Biodiversity \& Health Initiative' of the United Nations Convention on Biodiversity. Ecohealth offers a scholarly home to examine convergence, synthesis, and commonalities among these and other international initiatives, offering a space for issues that arise at the nexus of the work of International Panel on Climate Change; the Millennium Ecosystem Assessment (2005); the Commission on the Social Determinants of Health (2007), the United Nations Declaration on the Rights of Indigenous Peoples (2007) and the resilience-oriented Hyogo Framework of the International Strategy for Disaster Reduction (2007).

Part of the challenge for ecohealth as it matures will be questions of similarities and differences, spaces and 
overlaps, definition and identity in relation to these international efforts. Such questions are familiar to many maturing, boundary-crossing fields and for ecohealth, pose an ongoing challenge of framing, defining and valuing an explicit focus on synthesis and integration amidst individually compelling international processes and the relentless pressure for specialized focus. Collective and reflective attention to these challenges has characterized initiatives such as the international Communities of Practice in Ecosystem Approaches to Health and has the potential to become an important feature of ecohealth as an emerging field (Webb et al. 2010; Charron 2012).

The integrative space of ecohealth will continue to be defined not only by the precedents above, but also by the ongoing arrival of 'new friends and neighbors' that warrant and demand an opportunity to become better together. Notable developments on the international stage range from the momentum around 'healthy parks - healthy people' addressing nature's influence on physical health and mental well-being, to the explicit focus on the interface among human, animal and wildlife health offered by One Health initiatives especially in the context of (re)emerging infectious diseases. Likewise there is the persistent emergence of new terminology such as 'eco-bio-social' approaches to infectious diseases, growing attention to 'social-ecological' resilience and health building explicitly on the work of the Resilience Alliance, and the ongoing calls - in a variety of languages - for 'healthy land - healthy people' or 'healthy ice - healthy people' initiatives, especially in the context of Indigenous peoples (Parkes 2011). Rather than distractions, these diverse efforts represent ongoing quests to express the fundamental interrelationships of health and ecology in ways that reflect the reciprocity among humans, all species and the non-living components of the ecosystems on which we depend. In combination, these efforts challenge ecohealth to revisit its foundations as a transdisciplinary and inclusive space that celebrates diversity and the need for collective, integrative and also 'generalist' effort in the face of hyper-specialization.

The need for a common space to explore, question, challenge, engage, and celebrate the complementarity among diverse efforts was a core motivation for the 'gathering place' idea of the EcoHealth journal and the subsequent establishment of an international 'Association' in 2006. For many engaged with research and scholarship, ecohealth has created a space for exchange among integrated efforts that may be considered at the fringe of their respective fields within health sciences, natural sciences, social sciences or the humanities. Yet the full potential of ecohealth in research and practice will arrive by going beyond the traditional academic domains of discovery and teaching to recognize modes of inquiry more attuned with the complex challenges of the 21 st century, including the scholarship of integration, application and, engagement. In keeping with others navigating transdisciplinarity and integration, the challenge for ecohealth is to go beyond the integration of disciplines and the academy itself, to engage with a new generation of collective learning and action (Brown et al. 2010). By transcending disciplinary constraints, and learning how to meaningfully respect and engage with other forms knowledge, we may not only be able to better integrate and apply what we know, but also to address the wicked problems that ecohealth is a direct response to.

In terms of scholarship, peer review and publication, the foundational efforts of ecohealth are also set against the backdrop of change created by web-based publications, non-academic forums, open-access journals, and openended, public conversations between researchers, funders and those using or affected by research. These new technologies are proving influential in the evaluation of the quality and validity of information and how it is used. For an emerging field of inquiry such as ecohealth, these technological and social changes provide an opportunity for innovation, but also the potential become out-of-step with new frontiers of synthesis, learning, and integration. The Association and EcoHealth journal will need to be adaptive and responsive to these realities as part of a longterm engagement with the systemic connections of health, ecosystems and society.

Most would agree that the foundational efforts in the field of ecohealth have only begun to engage with these challenges. The next generation of work will demonstrate how well we respond to the issues raised here-especially the challenges of diversity, emergence, and resilience. Ecohealth will continue to find both strength and tensions in how it navigates the diversity it represents and should not be surprised by particularly persistent wrinkles that are not easily ironed out—notably issues around redundancy and territory, and among the conceptual and methodological divides that limit our ability to bridge the social and ecological in relation to health. We are also challenged and enabled by the emergence that is the result of the converging interests alluded to above, crossing a rich array of disciplinary, sectoral, cultural boundaries. If our understanding of complexity has taught us anything, this emergence will 
follow attractors we may never have imagined and yield surprises, unusual allies and unexpectedly rich and challenging results. Ultimately, the field of ecohealth, whose conceptual scope overlaps with that of resilience, is also challenged to be resilient itself. The design and learning challenges required to demonstrate scholarly, organizational and social-ecological resilience are not minor, but we must recognize that this is a multigenerational process that requires humility and commitment to ongoing learning. The Association and its journal enthusiastically invite you to be engaged in that ongoing process.

\section{Margot W. Parkes}

President, International Association for Ecology \& Health Canada Research Chair in Health, Ecosystems \& Society, School of Health Sciences, University of Northern British Columbia, 3333 University Way, Prince George, BC V2N4Z9, Canada

e-mail: parkesm@unbc.ca; mparkes@ecohealth.net

\section{REFERENCES}

Brown VA, Harris J, Russel J (2010) Tackling wicked problems: through the transdisciplinary imagination, London: Earthscan

Charron DF (Ed) (2012) Ecohealth research in practice: innovative applications of an ecosystem approach to health, Springer: New York; Ottawa: International Development Research Centre

Parkes MW (2011) Ecohealth and aboriginal health: a review of common ground. Prince George: National Collaborating Centre for Aboriginal Health. http://www.nccah-ccnsa.ca.

Waltner-Toews D (2011) EcoHealth: a primer. Veterinarians without Borders/ Vétérinaires sans Frontières. http://www.vwb-vsf.ca

Webb J, Mergler D, Parkes MW, Saint-Charles J, Spiegel J, Waltner-Toews D, et al. (2010) Tools for thoughtful action: the role of ecosystem approaches to health in enhancing public health. Canadian Journal of Public Health 101(6):439-441

Wilcox B, Aguirre AA, Daszak P, Horwitz P, Martens P, Parkes M, Patz JA, Waltner-Toews D (2004) EcoHealth: a transdisciplinary imperative for a sustainable future. EcoHealth 1(1):3-5

Zinsstag J, Schelling E, Waltner-Toews D, Tannera M (2011) From "one medicine" to "one health" and systemic approaches to health and well-being. Preventive veterinary medicine 101(3-4): 148-156

Published online: January 10, 2012 